\title{
LUTO DE ORIGEM: REPRESENTAR O QUE SE REENVIA COMO SE...
}

MOURNING OF ORIGIN: TO REPRESENT THAT

\author{
Piero Eyben \\ Universidade de Brasília \\ Brasília, DF - Brasil \\ ORCID 0000-0002-8427-3123
}

\section{Resumo}

A partir de alguns textos de Jacques Derrida, o presente artigo intenta compreender o que seria a tarefa e a origem (sempre compreendida como uma Rückfrage, "uma questão que retorna") da literatura enquanto articulação iterativa da desconstrução. O imperativo da escrita implica nos campos da desconstrução uma das formas de se repensar as fronteiras, as margens e os deslocamentos da responsabilidade e do papel performativo. Sendo assim, torna-se necessário tomar o discurso em plus d'une langue - em mais uma e nenhuma língua - na qual o aparato filosófico é trabalhado em seu como se literário. Numa inseparabilidade, literatura e filosofia se respondem nessa cena de rastros. Desde os prolongamentos do problema da aporia - uma espécie de demora e mesmo de uma restancia da demanda e do apelo - proporei uma reflexấo do quiasma entre filosofia e literatura, entre tradiçáo do pensamento e aquela da produção dos textos poéticos (de e a partir de Derrida).

Palavras-chave: Luto; Origem; Questão; Aporia; Como se.

\section{Abstract}

From some Jacques Derrida’s texts, this paper tries to understand what would be the task and the origin (always understood as a Rückfrage, "a question that returns") of literature as an iterative articulation of the deconstruction. The imperative of writing implies in the fields of deconstruction one of the ways to rethink the borders, the margins and the displacements of responsibility and the performative role. Thus, it becomes necessary to take the discourse in

\section{Résumé}

Dès certains textes de Jacques Derrida, cet article essaie de comprendre ce qui serait la tâche et l'origine (toujours compris comme Rückfrage, "une question qui renvoie») de la littérature en tant quarticulation itérative de la déconstruction. L'impératif de l'écriture implique dans les domaines de la déconstruction une des manières de repenser les frontières, les marges et les déplacements de responsabilité et le rôle du performatif. Ainsi, il devient 
plus d'une langue - in another and no language - in which the philosophical apparatus is worked on in its as if literary. In an inseparability, literature and philosophy respond in this scene of traces. Since the prolongation of the problem of aporia - a kind of delay and even a resting demand and appeal - I will propose a discussion of the chiasm between philosophy and literature, between tradition of thought and that of the production of poetic texts (from and by Derrida).

Keywords: Mourning; Origin; Question; Aporia; As if. nécessaire de prendre le discours dans plus d'une langue - dans un autre et aucune langue - dans lequel on travaille l'apparât philosophique comme s'il était littéraire. Dans une inséparabilité, la littérature et la philosophie se répondent dans cette scène de traces. Étant donné que les projections du problème de l'aporie - une sorte de retard et même une demande de restance et appel - il s'agit de proposer une réflexion sur le chiasme entre la philosophie et la littérature, entre la tradition de la pensée et la production de textes poétiques (de et à partir de Derrida).

Mots-clés: Deuil; Origine; Question; Aporie; Comme si.

No Diário do hospicio, Lima Barreto, ao se questionar sobre a loucura escreve: "Todo problema de origem é sempre insolúvel; mas não queria já que determinassem a origem, ou explicação; mas que tratassem e curassem as mais simples formas" (BARRETO, 2017, p. 55). Desse modo, para além do pressuposto apegado a uma cura da origem, Lima Barreto parece propor ver na loucura o que permanece estruturalidade aberta, ou melhor, uma espécie de devir de sua possibilidade, que especula não sobre a origem em si, mas antes sobre algo como uma originalidade de significaçóes que se sobrepóem ao aparato fechado de uma estrutura fechada do "problema da origem", da distensão de suas formas que não se apresentam como explicação, mas como diferimento infinito. Talvez por isso, prefiro me impor aqui uma pergunta que apenas poderei tentar responder por dois desvios iniciais, antes de me deter na questão do luto de origem.

Assim, como começar? Como, a partir do começo, pensar isso que poderia ser a origem, uma origem desde a desconstrução, se é que existe isso, a desconstrução, a origem ou mesmo a origem da desconstrução? E, no entanto, há aqui uma demanda em se pensar (o meio século da desconstruçáo). Mesmo que essa data signifique algo como já um deslocamento. Mesmo que talvez a data de 1962 
fosse a mais indicada e, portanto, não seriam 50, mas 55 anos. Nesse sentido, dois desvios breves. De um lado, tomarei a hipótese de que o trabalho da desconstrução começa ali onde Derrida, para pensar a origem, realizou uma tradução. Trata-se da tradução e introdução à Origem da geometria, de Husserl, e como nela está a condensação de um trabalho de mais de 40 anos, incluída aí a especulação sobre a tradução enquanto lugar privilegiado da desconstrução, lugar sobretudo de um indesconstrutivel. De outro lado, na segunda senda, para introduzir o espaço do que se coloca o luto antecipado, a noção de sobrevida, desde dois fragmentos de Jean-Luc Godard (1996), em JLG/JLG: autoportrait de décembre.

Entre os atos necessários e impossíveis para Derrida está aquele da tradução. Não à toa, penso, ele comece por aí. Ela é, como diz em Des tours de Babel, “[...] l'effet d'une lutte pour l'appropriation du nom, nécessaire et interdite dans l'intervalle entre deux noms absolument propres" (DERRIDA, 1998, p. 207). Na disjunção entre duas línguas, ao menos duas línguas ou mais de uma língua, a tradução deve dispor-se diante daquilo que é absoluto e enfrentar a propriedade daquilo que náo parece ser apropriável. A tarefa de traduzir coloca, como se pensa costumeiramente, o tradutor em dívida com o original. E é justamente esse aspecto que Derrida coloca-se a tarefa de desconstruir. A expedição do tradutor parece ser sempre a de uma "restituition du sens" (DERRIDA, 1998, p. 212) ali onde ele também deve abandonar essa possibilidade. Esse envio, que está na postulaçáo benjaminiana da tarefa/renúncia do tradutor, toma o dado (ato de uma recepção e comunicação) não como uma reprodução, mas, deslocando o polo, postula o texto dito original num a-traduzir. Todo original é um a-traduzir, que sobrevive na mutação de uma língua a outra. Desse modo, trata-se de tocar "ce bord à l'autre du nom propre" (DERRIDA, 1998, p. 219), onde o original também começa a se endividar. Aquilo que é intocável permanece na tradução intransmissível enquanto tal. E, assim, apenas quando uma reconciliação entra em cena, é que a tradução pode soar como uma promessa “qui arrive à promettre la réconciliation" (DERRIDA, 1998, p. 224). A promessa, destituída de seu sentido ordinário, é um engajamento performativo que deve ser sempre renovado e assombrado por seu perjúrio. Ela pode náo representar o comunicativo de um texto dito 
original, mas deve tomar a "origine de l'original à traduire”, pois “[...] si l'original appelle un complément, c'est qu'à l'origine il n'était pas là sans faute, plein, complet, total, identique à soi" (DERRIDA, 1998, p. 222).

O que permanece, então, idêntico ou repropriável? $\mathrm{O}$ acontecimento de uma corporeidade outra, de uma decisão que coloca a tradução como mais original por não haver tradução de uma tradução. $\mathrm{O}$ contrato de tradução não existe sem contar com uma afirmaçáo importante de Qu'est-ce qu'une traduction "relevante"?: "[...] la relevance $[. .$.$] , ce sera ce qui justement arrive à la chair du texte, au$ corps, au corps parlé et au corps traduit - quand on s'endeuille de la lettre pour sauver le sens" (DERRIDA, 2005a, p. 34). A relevância de uma tradução é sua Aufhebung não finita, não totalmente interiorizada numa síntese. É ela uma distensão do apropriável, daquilo que pode definir-se como o que ocorre no corpo do texto. Desse modo, em toda origem, há já esse enlutamento diante da salvação do sentido, de sua retenção, como veremos mais adiante. Trata-se de um corpo à traduzir e traduzido, solicitado enquanto tradução desde a origem. Na dívida de Antonio a Shylock, no Mercador de Veneza, está justamente a cerne do texto - o respeito ao contrato tradutório que sela a aliança. No entanto, haveria algo como uma escritura sem dívida em cada tradução, justo enquanto o tomamos como luto impossível, como impossível incorporação e, logo, impossível sus-preensão.

Como segundo desvio, Godard, em JLG/JLG, diz, ele mesmo:

\author{
d'habitude \\ cela commence \\ comme cela \\ il y a la mort \\ qui arrive \\ et puis \\ l'on se met à porter \\ le deuil \\ je ne sais \\ exactement pourquoi \\ mais jai fait
}


l'inverse

chambre noire

j'ai porté le deuil

d'abord

mais la mort n'est pas venue

ni dans les rues

de Paris

ni sur les rivages

du lac de Genève

lanterne magique

(GODARD, 1996, p. 8-10)

Trata-se, pois, de um costume. Talvez uma lei muito anterior que estabeleça por começo a vinda da morte para que depois ocorra o luto. Lei, como todas, econômica, em que os rituais da morte tendem a exceder a experiência da morte do outro. Nesse autorretrato, Godard diz, por si mesmo, vale repetir, que seu luto já começou antes mesmo de começar. Ele tem origem na imagem captada, de si e para si, como reconhecimento do outro nele. Talvez aqui a forma da "incorporação paradoxal' (DERRIDA, 1993, p. 25) do espectro da qual fala Derrida, em que a aparição é sempre já uma reaparição do desaparecido. Paradoxal, exatamente porque não há incorporação possível já que o devir-corpo do espectro permanece como essa espécie de resto entre corpo e espírito, alcançando apenas uma temporalidade que está desajustada, disjuntiva, nem totalmente presente, nem totalmente ausente. Aquele que desapareceu apresenta essa dificuldade do nome - impossível de ser traduzido por um simples trabalho de luto - e insiste, portanto, em continuar reaparecendo, como que tomado de sua chegada também impossível. Qual seria o acontecer do espectro? Enquanto aparição, sua vinda se demora, voltando. $\mathrm{O}$ texto de Godard parece jogar com isso. O que começa, como hábito, é certa precedência da morte sobre o luto. No entanto, vale perceber o uso dos sujeitos aqui: isso começa, há a morte que chega, porta-se o luto. As formas impessoais da lei do nómos, fazendo parecer que constituem a origem do modo de lidar com o luto, isto é, para usar um termo de Freud, o Normalaffekt der Trauer, contrário (binariamente) à "pertur- 
bação psíquica narcísica [narzißtischen Seelenstörungen] da melancolia" (FREUD, 2013, p. 45). Desse modo, todo o investimento precisaria ser retirado daquele objeto que, no entanto, não é parte do $e$, como também afirma Freud, mas sim do mundo. Talvez aí essa existência destituída de um sujeito de assunção do luto. O texto não se detém aí e, ao questionar uma origem para o costume do luto, introduz justamente o autorretratado: eu não sei exatamente porque mas fiz o inverso. E é dessa inversão que se trata a aparição espectral, a impossibilidade de uma incorporação total do objeto perdido. Fazer o inverso aqui é desde já dar lugar a um acontecimento, logo, irrepetível e surpreendente. Faço questão de impor meus olhos e ouvidos sobre isso que Godard propôs aqui: uma distopia, uma reversão, um sentido outro para o tempo da morte - que ocorre, que chega a todos - e do luto. O antes e o depois da história. Sem saber do começo ou dos porquês do começo, ele porta um luto anterior. Ele o coloca na origem.

Primeiramente, o luto é portado para depois se morrer. E é o verbo porter que porta isso, já que pode querer-dizer carregar, mas carregar aquilo que se tem de mais íntimo, de mais próprio, de mais seu. Carregar, não como quem carrega um fardo apenas, mas como uma marca de propriedade do ser ou da espécie. Se digo eu porto, posso dizer que tenho em mim, antes de qualquer coisa, essa atribuição que sequer foi atribuída por outrem, mas que permanece como inata, imprescindível ao sujeito que a porta. E, nesse caso, portar o luto seria sempre anterior, sempre primeiro, independente da prova de realidade que "[...] mostrou que o objeto amado já não existe mais e agora exige que toda a libido seja retirada de suas ligaçóes com esse objeto" (FREUD, 2013, p. 49). Já que a morte não veio (nem nas ruas de Paris nem no lago de Genebra), trata-se sempre de dois artifícios que sáo propriedade mais imprópria dessa voz: câmara escura e lanterna mágica. O prolongamento aqui é visto desde a possibilidade de se guardar a imagem dessa vinda que não chega, manter, portanto, algo que é essa anterioridade (do luto sobre a morte) num arremesso temporal diante do porvir. Nesse tempo, talvez não importe a devoração canibalística que sugere Freud, mas antes, como propóem Nicholas Abraham e Maria Torok, numa espécie de luto interminável para o preenchimento de bocas vazias na introjeçấo do objeto perdido, "l'acte de mettre en mots le vide oral originel" (ABRAHAM; TOROK, 
1987, p. 268), a destruição fantasmática por uma linguagem figurada. O que ele porta? Um eu que não sabe; um eu que, apesar de antecipar o luto sobre a sua morte, sabe da morte do outro porque está nele esse vazio de origem. Alguns minutos depois, Godard ainda diz:

\author{
non, jeetais déjà \\ en deuil \\ de moi-même \\ mon propre \\ et unique compagnon \\ et je me doutais \\ que l'âme \\ avait trébuché \\ sur le corps \\ et qu'elle était repartie \\ en oubliant de lui tendre la main \\ sein und zeit \\ donner à voir \\ (GODARD, 1996, p. 12-13)
}

E trata-se mesmo disso, dar a ver? Não podemos esquecer que se trata de um autorretrato (em dezembro). Não podemos esquecer que Godard intenta aqui dizer do inverno de sua própria vida, a partir de uma fotografia sua muito jovem, quase como uma sombra, quase como um daqueles perfis antigos em que se vê apenas o fundo branco sobre uma tinta negra. $\mathrm{Na}$ luz que seria talvez muito obscura para dizer do luto a que estamos todos desde sempre, desde já, imputados. É preciso, diz ele, dar a ver o que é esse luto anterior à morte, esse luto que o permite escrever esse filme. Dar a ver o que ele chama também de moi-même mon propre. Aquilo talvez que Ser e tempo náo tenha conseguido dar a ver, por demasiadamente preocupado com o propriamente morrer. Aquilo que apenas um filme que antecipa essa morte e a transforma originalmente em luto pode dar a ver, quando a alma já se estrebucha, tropeça no corpo. Ela tinha tropeçado sobre o corpo. Esse particípio lembra imediatamente, ao menos pra mim, uma arma de guerra. O trébuchet, o trabuco, essa espécie de arma de sítio, 
para cercar as cidades. Aquilo que esmaga as fortalezas. E, ao mesmo tempo, esse nosso verbo táo português quanto possível: estrebuchar (estremecer compulsivamente, sacudir-se, afligir-se emocionalmente, quase morrer de agonia, no fim).

Se é possível pensar a origem para fora de um espectro original, em que medida é ela já fantasmada por seus envios? Derrida parece apontar para esse espaço ao tratar "la trace (pure) como différance, a différance como formation de la forme” (DERRIDA, 1967b, p. 92), como lugar do acontecimento que insiste em retornar ali onde náo há retorno como tal, propriamente dito. No desdobramento da obra de Derrida, esse retorno, para além do espectro, talvez seja melhor definido ou delimitado pelo desenvolvimento operacional da noção quase-transcendental de revenant: o que vem, o que insiste em chegar ou permanecer chegando, o revir do fantasma, o retorno, o wake de Tim Finnegan; ou como sugere o poema de Baudelaire: "Et vers toi glisserai sans bruit / Avec les ombres de la nuit [...] Tu trouveras ma place vide [...] Sur ta vie et sur ta jeunesse, / Moi, je veux régner par l'effroi" (BAUDELAIRE, 1961, p. 70). A espectrologia do lugar aqui é fundamental. $\mathrm{O}$ acontecimento é um ter lugar (avoir lieu) ali onde nada terá tido lugar senão o próprio lugar. A disseminação do verso de Mallarmé parece ser uma das primeiras forças disso que implica as condiçôes de dizer o impossível, dizer o acontecimento. Valeria perguntar-se de que lugar é o lugar do acontecimento. Esse espectro de um espaço vazio, deixado vazio, por onde se desliza e o terror surge como forma de reinar sobre a vida e a juventude constitui o mundo como lugar do acontecimento, o mundo enlutado que antecipa o porvir. Trata-se mesmo de pensar um mundo que começa onde termina sua singularidade.

A cada vez, a expressão de Derrida é precisa. O mundo termina a cada vez, singularmente. E é nessa temporalidade que a demanda pela origem se faz necessária ou possível. Perguntar pelo onde ou quando começa a própria filosofia ou por quais desígnios se poderia começar a falar tem sido desde muito cedo uma das tentativas de incorporar, introjetar em si esse luto antecipado de origem. Como se fosse possível uma economia do luto, um trabalho de luto que se constrói dentro da possibilidade mais interiorizante do sujeito. De algum modo, nos diz Derrida, todo luto é impossível, uma vez 
que dependeria de um ato de fidelidade infiel (e mortífera) ao outro morto. Ser mais fiel aqui dependeria do deixar o outro partir sem introjetá-lo num si, numa ipseidade daquele que permanece(u) vivo. Nesse sentido, ao não interiorizar na memória (a Erinnerung em ato), a experiência do fim do mundo se dá como singularidade absoluta, irruptiva da violência da única morte que é vivenciável: essa do outro. Numa memória sempre enlutada - como a traduçáo - começa toda especulação derridiana pela origem. Trata-se aqui necessariamente de uma escrita arqui-escritural da ausência, portanto, de um ponto (a metáfora geométrica não se faz aqui ao acaso) de chegada, de um ponto de basta, de uma imagem primeira, de um umbigo do sonho. A origem, ou melhor o luto de origem resiste a toda introjeção ou incorporação. Ele impossibilita-se enquanto totalidade ou supra-assunção (sus-preensáo) diante do objeto perdido (sempre já perdido objeto da idealidade). Se há algo que excede aqui uma origem, ele surge não como uma presença conservada e/ou abolida, antes ela se marca como diferenciação, como deslocamento de ausências que se escrevem apenas como o que se envia, como pergunta demandando um envio, uma resposta, uma responsabilidade pelo dizer dessa origem não-original, dessa única origem a cada vez singular como tradução de um luto impossível.

Antecipação do inantecipável, o porvir não pertence ao cálculo de um futuro. Ele permanece por vir, uma chegança que apenas se dá cheio de restos, como efeito de restance. O resto fica [le reste reste] e não se calcula, assim como a resposta contra o sujeito. Nesse sentido, o mundo só começa com seu afastamento, com seu fim. $\mathrm{O}$ verso de Celan tantas vezes analisado por Derrida, Die Welt ist fort ich muss dich tragen, aponta para esse começo impossível. Trata-se disso mesmo: portar o outro como um dever diante do fim de sua idealidade ontológica, arqueológica. Qual o fim da origem? De um lado, vale perguntar onde ele termina, qual o seu final, onde ele acaba de se originar? De outro, a demanda por sua finalidade, por sua propriedade mais própria, por sua funcionalidade enquanto dar início a algo como o pensamento ou a poesia. As condiçóes de possibilidade, por fim, da origem parecem esbarrar nisso que se dá apenas como resto ou rastro, nisso que pode soar apenas como excesso de propriedade, mas que, ao questionar o como tal da coisa, implica já reimaginar 
suas condiçốes de possibilidade, seu como se, o tomar o impossível desde as condiçóes de possibilidade da própria impossibilidade. Dito de outro modo, a origem como efeito de diferença não se dá senão sob o assombro, a reaparição disso que é impossível nela mesma, em sua condição sempre já lá, ou sempre já antecipatória de algo que já não é a origem, mas apenas uma espécie de estruturalidade de seu fim. Se insisto nesse ponto é que nele parece-me residir aquilo que porta a origem: um distanciamento náo introjetivo ou incorporável do fim, da sua singularidade, uma distância irremediável que excede qualquer cálculo por sua determinaçáo, por sua colocação em termos. Se o fim do mundo implica o dever portar o outro, que mundo se origina aí? A que mundo nos antecipamos? O luto de origem está sempre já lá, sempre já assombrando a presença de um ato original. É de luto que se trata, de uma memória enlutada, traduzida nisso que parece ser a dívida impagável diante do nome do outro, e náo de uma essencialidade ideal diante do começo, dos princípios, da origem, da filiaçáo, do primeiro dito.

$\mathrm{O}$ ato de escrita convoca essa resposta pelo sentido que apenas faz sentido numa espécie de fim infinito, na demanda da finalidade do infinito. Se tomarmos a afirmação de Celan não como mera expressão idiomática para um mundo acabado, mas antes como uma afirmação performativo-constativa que introduz uma proposição acerca do mundo, de sua finalidade em si (se é que isso existe), poderíamos estar diante da origem do mundo enquanto ilegibilidade formadora da distância. Die Welt ist fort... introduz necessariamente a lonjura do mundo como seu atributo, como aquilo que pode existir, desde que haja mundo. Se há mundo, há esse longe, que é desde já aniquilante. A distância é, nesse sentido, a destruição do mundo e, ao mesmo tempo, sua origem atributiva mais própria. Se há mundo, há fim; ou dizendo de um modo outro, se há mundo, ele se partilha e na partilha o sentido se aniquila, por violentamente distanciado, por ser impossível ao outro tomar o outro como Um, fonte de toda destruição.

A última entrevista que Derrida concedeu recebeu um título no mínimo inquietante: Apprendre à vivre enfin. Isso ao menos de três pontos de vista. (1) Aprender a viver não seria a tarefa da filosofia, que se pautou desde Platão no Fédon ao menos, no aprender a morrer, 
nessa incorporação que é uma espécie de movimento da afirmação da imortalidade da alma individual ou, mais precisamente, a epimeleia tes psykhes (cuidado com a própria alma) como melete thanatou - "le soin pris de la mort, l'exercice de la mort, le 's'exercer à la mort" (DERRIDA, 1999, p. 29). Ou ainda, como aponta Montaigne, num de seus ensaios: "cependant s'empescher du pensement de chose si esloignée, ce seroit folie", como mesmo espaço do "engajamento à parte do corpo" [l'embesongnent à part du corps] da alma fora de nós, o que equivaleria a uma tarefa acima da própria filosofia e de um tempo do eu (e não preciso dizer que Montaigne aqui decreta esse tempo afirmando ter feito 39 anos); (2) o verbo apprendre que pode indicar um aprendizado e um ensinamento, uma duplicidade do filósofo que está na posição de professor e aluno invariavelmente, em sua consciência de que é ele também um vivente, logo, um ser morrente que, quando fala da morte, fala de si mesmo como outro, enquanto o outro que ele vê morrer; (3) esse enfim que implica uma decisão imperativa e irrevogável acerca do tempo da vida (e náo apenas da morte como limite último). O que pode querer dizer esse enfim? Proponho que o leiamos de quatro formas simultaneamente: finalmente, o fim, em lugar do fim e definitivamente. Ou seja, trata-se de uma temporalidade que se demanda pelo fim, mas sobretudo um fim que se coloca como pergunta primeira. $\mathrm{O}$ que vale aprender da filosofia? $\mathrm{O}$ que faz a filosofia definitivamente? Qual a sua finalidade última? $\mathrm{O}$ que faz um texto (filosófico) quando se coloca no lugar do fim? É nossa tarefa perguntar-se sobre o fim?

Derrida começa sua especulação pelo senso comum desse aprender a viver enfim, esse sentido claro de amadurecer e educar "apprendre à l'autre et surtout à soi-même" (DERRIDA, 2005b, p. 23). Não sem se esquecer da ameaça contida na proposição, a tarefa aqui é partilhar herança e morte no ensino da vida diante da mortalidade absoluta e, logo, tentar responder à "Comment répondras-tu de ta vie et de ton nom?” (DERRIDA, 2005b, p. 24). Esse aprendizado/ensino implica uma demorança da sobrevida, sua suspensão por compreender survivants en sursis, visto que a vida é a própria sobrevida - aquela para além da vida (Überleben) e em seu adiamento protelado em uma distância (Fortleben). O rastro espectral dos sobreviventes exige partilhas que são o próprio ethos da escritura, sua incorrompitilida- 
de. Derrida afirma: “[...] si j'avais inventé mon écriture, je l'aurais fait comme une révolution interminable" (DERRIDA, 2005b, p. 31). Dessa invençâao possível, de sua condição de possibilidade, é que aparece o espaço de um luto de origem que provém a morte ou a finalidade que é experimentada desde a escrita. É na escrita que a vida da morte (por paradoxal que seja esse impasse) pode ser prova$\mathrm{da}$, ou mais precisamente, a revolução interminável aqui se faz numa afirmação agônica do eu que pode dizer, simplesmente que "[...] je vis ma mort dans l'écriture. Épreuve extrême: on s'exproprie sans savoir à qui proprement la chose qu'on laisse est confiée" (DERRIDA, 2005b, p. 33-34). A herança desse luto interminável necessariamente implica uma expropriação do que não se faz por escolha - já que não se escolhe o que se herda - mas no trato violento da língua como algo que não nos pertence, algo que não se toma como próprio. É na impropriedade do que nos é confiado (ou do que deixamos confiado ao outro) que uma espécie de preocupaçáo, um cuidado incondicional torna-se afirmaçáo da vida - o próprio tomar partido da desconstrução, já que "[...] tout le temps, la déconstruction est du côté du oui, de l'affirmation de la vie" (DERRIDA, 2005b, p. 54) onde sobreviver precisa ser tomado como impulso último e extremo, "[...] le survivre à la mort, car la survie, ce n'est pas simplement ce qui reste, c'est la vie la plus intense possible" (DERRIDA, 2005b, p. 55). A guerra de Derrida aqui é por uma afirmação intensiva do estar diante do outro. Provação extremada: sobrevive-se à morte, até a morte, na extenuaçáo dessa tentativa de continuar vivente. $\mathrm{O}$ pensamento em direção à morte é um pensamento do fim, sem dúvida, mas o fim em sua finalidade de responsabilidade em tomar um nome à morte, portar o nome do outro morto. Exercitar-se à morte recebe aqui uma outra significação: aquela da afirmação extremada da vida enquanto modo do acontecimento que sobrevive à própria morte.

Seria, pois, todo luto de origem um modo de pensar a origem? Freud diz precisamente: "[...] no luto é o mundo que se tornou pobre e vazio; na melancolia é o próprio eu" [Bei der Trauer ist die Welt arm und leer geworden, bei der Melancholie ist es das Ich selbst] (FREUD, 2013, p. 53). Em sua dialética entre luto e melancolia, ou na dinâmica da própria psicanálise, o luto é sempre compreendido como econômico diante do poder devastador da melancolia que em- 
pobrece e esvazia o eu. Valeria perguntar quando o mundo é menos importante que o eu, ou melhor, se é possível uma escrita que seja sem o mundo. Talvez, e essa é uma hipótese importante, toda escrita seja desde já uma escrita do luto. Sua singularidade, seus efeitos de singularidade não repetíveis produzem o acontecer da escrita a partir da dessa perda ou desse ter se tornado [geworden] pobre e vazio. Já que:

Car chaque fois, et chaque fois singulièrement, chaque fois irremplaçablement, chaque fois infiniment, la mort n'est rien de moins qu'une fin du monde. Non pas seulement une fin parmi d'autres, la fin de quelqu'un ou de quelque chose dans le monde, la fin d'une vie ou d'un vivant. La mort ne met pas un terme à quelqu'un dans le monde, ni à un monde parmi d'autres, elle marque chaque fois, chaque fois au défi de l'arithmétique l'absolue fin du seul et même monde, de ce que chacun ouvre comme un seul et même monde, la fin de l'unique monde, la fin de la totalité de ce qui est ou peut se présenter comme l'origine du monde pour tel et unique vivant, qu'il soit humain ou non (DERRIDA, 2003, p. 23$)^{1}$

A tentativa de representação desse mundo que se perde, que chega a um fim, é toda tarefa da escrita como um envio interminável de sua singularidade. É insubstituível porque marca esse cada vez único. Essa marca, em Derrida, é sempre uma remarca [remarque]. E é preciso entender que há uma espécie de histórico de transformação desse quase-conceito na obra de Derrida. Lá no começo, em La dissémination (precisamente no texto sobre Mallarmé e Platão), ele utiliza a palavra remarque (que no idioma de Derrida não é evidente, porque pode querer dizer remarca, ou apenas uma atenção, uma observação). Em seguida, o termo acaba tomando a forma de retrait que também

1 Tradução: "Pois cada, e cada vez singularmente, cada vez insubstituivelmente, cada vez infinitamente, a morte é nada mais nada menos do que um fim do mundo. Não só um fim, entre outros, o fim de alguém ou de algo no mundo, o fim de uma vida ou de um ser vivo. A morte náo coloca um término a alguém no mundo, nem a um mundo entre outros, ela marca cada vez, cada vez ao desafio da aritmética, o absoluto fim de um só e mesmo mundo, de que cada obra como um só e mesmo mundo, o fim do mundo único, o fim da totalidade do que é ou pode se apresentar como a origem do mundo para tal e único ser vivo, seja humano ou não.” 
não é evidente, já que pode significar tanto "saque", quanto "retraço", "retirada", "aposentadoria". De certo modo, trata-se de um caminho ainda não trilhado (aliás, essa é uma palavra para se entender também a re-marca, que segue como uma tentativa de explicaçáo da palavra frayage, a traduçáo de Derrida para Bahnung, que foi traduzido por "exploraçáo", mas que gosto do sentido mais abrasileirado de "picada", "fazer uma picada na mata", "desbravamento"). A abertura desse mundo (único e mesmo mundo) implica o fim da totalidade da origem do mundo, de sua apresentação como origem do mundo. E, daí, a preocupação com a representação que não pode contentar-se com certa noção de tornar presente, re-apresentar na presença do presente a marca identitária dessa origem náo encontrável. Trata-se sempre de um desbravamento daquilo que é rastro.

$\mathrm{Na}$ Introduction à l'Origine de la géométrie, de Husserl, Derrida apresenta sua tradução não apenas como tradutor, ou sobretudo, como um tradutor que intenta compreender essa sobrevida. A pergunta inicial do texto se debruça sobre a "identificação do mesmo" nos objetos ideais da ciência, isto é, a geometria. Assim, ele começa por algo como as condiçóes de possibilidade dos objetos ideais. Sem deixar de lado a ideia fenomenológica da redução, Derrida sempre as coloca umas contra as outras, mostrando que as condiçôes de possibilidade, por certo, parasitam a idealidade da origem, mostram que qualquer origem já, ou desde sempre, foi rasurada por algo aparentemente posterior a ela. Trata-se, portanto, de rediscutir a historicidade de certa originalidade da geometria e do discurso da geometria.

Como "tarefa infinita" (DERRIDA, 2009, p. 5), Derrida tenciona abrir um despertar do sentido da história - talvez sua pergunta mais profunda desde sempre. Assim, ele tenta demonstrar algo que já está reduzido em seu sentido fenomênico. Algo como que para além do sentido da "[...] unité d'une histoire, il s'agit de l'unité de traces, de 'renvois', de 'résidus' des synthèses à l'intérieur de la sphère égologique pure" (DERRIDA, 2009, p. 7). Essa "unidade de rastros" talvez venha aqui para mostrar aquilo que esteve sempre recalcado, reprimido na história dos objetos ideais, como objetos superiores da razão, como aqueles que seriam os únicos a assegurar a possibilidade da historicidade, já que os rastros dizem de algo que desde sempre já foi reiterado, repetido, reenviado, que é residual na origem. $\mathrm{O}$ rastro 
não implica, no entanto, uma espécie de crise nas ciências ou na filosofia: porque não esquece as origens. Não se trata de simplesmente inverter, de uma inversão - Umkehrung, na palavra de Husserl que Derrida chama atenção (DERRIDA, 2009, p. 13) - da relação de dependência. É preciso antes um movimento em parafuso [mouvement en vrille] (DERRIDA, 2009, p. 14) - e não sem lembrar o the turn of the screw, de Henry James.

Derrida chama atenção, portanto, para aquilo que Husserl intenta chamar de origem da geometria, que está no fundo para fora da geometria por si mesma. Ele apresenta uma noção histórica, algo como "uma repetição de origem", mas de uma "reflexão segunda" (DERRIDA, 2009, p. 15), "[...] la réflexion n'opère pas sur ou dans la géométrie elle-même” (DERRIDA, 2009, p. 14).

Assim, a pergunta sobre a questáo da origem pode, como condição de sua possibilidade, ater-se à ideia de finitude, sobre aquilo que pode ser definido pela história como o começo. Derrida afirma que a origem depende do infinito já colocado: “[... l'infini avait déjà fait irruption, il était déjà au travail lorsqu’à commencé la première géométrie qui était déjà, elle aussi, une infinitisation" (DERRIDA, 2009, p. 18). Sua anterioridade depende de um itinerário daquilo que já estava em trabalho naquilo que se concebeu como "primeira geometria”. Trata-se de um parêntese na história, mas um parêntese importantíssimo: apenas na confusão do objeto já pronto com aquilo que se pode reduzir desse objeto é que nasce a consciência de uma origem. E, ali, a intuição da essência, já que “[...] objetos ou objetividades que ela [intuição] visa não existiam antes dela; e esse antes de da objetividade ideal marca mais que a véspera cronológica de um fato: uma pré-história transcendental" (DERRIDA, 2009, p. 23). É preciso dizer, com Derrida, há sempre algo já lá, sempre já. E que o sentido e despertar das origens aparece como uma possível alucinação da primeira vez.

A Erstmaligkeit (essência de primeira vez) é, alerta Derrida, reprodutível - não a "facticidade do fato", mas o "sentido do fato" (DERRIDA, 2009, p. 33), uma vez que só ele dá origem a um discurso e a uma determinação. A necessidade de ter havido uma origem só se dá após, o já constituído vem com o sentido do fato, que assume seu a priori. Trata-se da Rückfrage, uma questão em retorno, que se 
faz desde um primeiro envio. Toda origem dependeria, como forma de escape à essencialidade da origem toda, dessa pergunta que retorna e que, ao voltar, estabelece-se na distância iso-crono-tópica do tempo das origens. Dito de outro modo, trata-se, sobretudo, de um regresso em que a suspensáo do sentido de um mundo que se perdeu - como o próprio desdobramento do luto do eu que porta primeiramente o luto, o porta antes da morte (que acaba por náo vir, como alertou Godard), acaba por portar o mundo que se perde. Nesse sentido, à perda singular do mundo estende-se a perda singular desse eu que tenta retornar ao afeto normal, numa economia da possibilidade em erigir um onde e quando se iniciaria um fim. Daqui, a sua secundidade de origem. Ela é apenas possível disposta numa história não-linear, cronológica, mas num messianismo - reenviada, remetida para além da possibilidade de uma delimitação de sua própria pergunta. $\mathrm{Ou}$ como diz Derrida é "[...] a partir do documento recebido e já legível, a possibilidade de interrogar novamente e em retorno me é ofertada, sobre a intenção originária e final do que me foi entregue pela tradição" (DERRIDA, 2009, p. 36). Voltamos à herança, à doença em si dessa pergunta infinitamente em retorno que é o luto impossível.

O campo histórico escondido se faz como possibilidade de reativação da coisa (chamada geometria). E é desde esse espaço que poderíamos imaginar uma espécie de método da leitura derridiana, ou seja, a assunção do indecidivel, em que o sentido está apenas ligado a "alguma referência irredutível ao ideal de decidibilidade" (DERRIDA, 2009, p. 40). A insistência por uma origem indecidivel se dá porque

[...] a indecidibilidade não tem um sentido revolucionário e desconcertante, ela não é por si mesma senão se ela permanece essencialmente e intrinsecamente assombrada em seu sentido de origem pelo telos de decidibilidade do qual ela marca a irrupção. (DERRIDA, 2009, p. 40, nota).

A sedimentaçáo do sentido está nessa distensão ao porvir do indecidivel contra a retenção temporal da origem. A historicidade irredutível do devir proporia um estar já lá no começo como desígnio presente desde a origem em sua totalidade (DERRIDA, 2009, p. 50). 
Então nessa irrupção é que Derrida propóe que a leitura deva ser realizada sempre retroativamente, visto que a objetividade é engendrada sempre a posteriori. Quando o aparato teleológico dos começos se constitui como tentativa de tomar o sentido como originário, como "constituição de um objeto", quando "[...] o sentido do sentido em geral que é aqui determinado como objeto, isto é como coisa disposta e disponível em geral e primeiramente por um olhar" (DERRIDA, 2009, p. 54).

É nessa dimensão que Derrida vai propor caminhar pela senda da intersubjetividade que deriva de certa noção de linguagem e escritura. Para desconstruir o antes e o depois dos objetos ideais, ele manifesta a intenção de propor um se, uma condição de possibilidade em que se pode fundar o aparecer da coisa. Nessa prospecção do sentido, ele afirma:

Intersubjetividade é então, primeiramente, de certo modo, a relação não empírica de mim comigo, de meu presente atual com outros presentes como tais, isto é, como outros e como presentes (como presentes passados), de uma origem absoluta com outras origens absolutas, que são sempre minhas apesar de sua alteridade radical. É graça a essa circulação dos absolutos originários que a mesma coisa pode ser pensada através momentos e atos absolutamente outros. Retornamos a isso sempre em última instância: a forma única e essencial da temporalização. Por sua própria dialeticidade, a originalidade absoluta do Presente Vivente permite a redução, sem negação, de toda alteridade; ele constitui o outro como outro em si e o mesmo como o mesmo no outro (DERRIDA, 2009, p. 82-83)

Algo como uma ausência ou virtualidade aqui impóe a necessidade da escritura. É ela a condição diante do sujeito falante incapaz de produzir uma reduçáo do objeto ideal. É ela que constitui essa alteridade no presente. A escritura pode ser original quando pode passar de seu sentido e, por isso mesmo, pode se apresentar como possibilidade de constituição -

[...] ela é a condição sine qua non de sua conclusão interna. Enquanto ela não esteja gravada no mundo, ou antes 
enquanto ela não possa sê-lo, enquanto ela não esteja na medida de se prestar a uma encarnação ou a uma roupa, a objetividade ideal não está plenamente constituída. $\mathrm{O}$ ato de escritura é então a maior possibilidade de toda constituição. (DERRIDA, 2009, p. 86).

Isso se dá porque é esse ato constitutivo sempre assombrado pelo sentido do outro e, assim, toda originalidade é já um reenvio, uma remissão, que aparece como desaparecimento ou numa forma residual em que a equivocidade responde por um horizonte arruinado ao tentar se perguntar, como faz Derrida, se "é legítimo falar de uma origem?" (DERRIDA, 2009, p. 141). A manutenção de uma origem absoluta, do como tal da origem esbarra nesse atraso do presente vivente que aponta a iterabilidade como "limite infinito de um movimento inacabado de fato" (DERRIDA, 2009, p. 148). Desse modo, Derrida propóe que há sempre uma origem anterior e uma alteridade da origem (DERRIDA, 2009, p. 170), que ela se dá apenas por diferimento, por différance (DERRIDA, 2009, p. 171).

Ali onde se divide e se apraza a origem, a différance se torna a operação suplementar - é um dos argumentos de La voix et le phénomène - como designação da "[...] fonction de suppléance substitutive en général, la structure du à la place de' (für etwas) qui appartient à tout signe en général" (DERRIDA, 1967a, p. 103). Assim, a origem repete possivelmente sua condição mesma de possibilidade, um ato produtor. Não se escapa aqui da natureza do rastro, disso que:

[...] on doit pouvoir dire a priori que leur racine commune, la possibilité de la ré-pétition sous la forme la plus générale, la trace au sens le plus universel, est une possibilité qui doit non seulement habiter la pure actualité du maintenant, mais la constituer par le mouvement même de la différence qu'elle $y$ introduit. Une telle trace est [...] plus "originaire" que l'originarité phénoménologique elle-même. L'idéalité de la forme (Form) de la présence elle-même implique en effet qu'elle puisse à l'infini se ré-péter, que son re-tour, comme retour du même, soit à l'infini nécessaire et inscrit dans la présence comme telle; que le re-tour soit retour d'un présent qui se retiendre dans un mouvement fini de rétention; qu'il n'y ait de vérité originaire, au sens phénoménologique, qu'enracinée dans la finitude de cette rétention; que ler apport à l'infini 
ne puisse enfin sinstaurer que dans l'ouverture à l'idéalité de la forme de présence, comme possibilité de re-tour à l'infini. (DERRIDA, 1967a, p. 79-80)

A repetiçáo da origem suplementa infinitamente e não simplesmente alivia por uma substituição incessante do agora na presença de uma perda. É disso que trata o luto de origem. Nele está esse reenvio do originário ao original, constituindo uma repetiçáo constituinte da memória em nome de uma dada origem. O porvir de uma promessa é sempre reengajada por ser já outra promessa, por mostrar-se como desafio à qualquer reapropriação dos códigos de interiorização do ato original. Erinnerung impossível, a memória do rastro é aqui uma possibilidade de livrar-se ao infinito, exercitar-se ao extremo numa decisão enlouquecida diante do outro que está, ele também, enraizado numa retenção original.

Nesse luto de origem está uma loucura, logo, uma decisão que náo pode simplesmente antecipar seu porvir, mas que, no entanto, pede uma tradução, uma reaparição espectral [revenance]. À distância, o fim começa a descer, como a morte de Baudelaire, "planant comme un soleil nouveau” (BAUDELAIRE, 1961, p. 153).

\section{Referências bibliográficas}

ABRAHAM, N.; TOROK, M. Deuil ou mélancolie: Introjecter - Incorporer. In: . L'écorce et le noyau. Paris: Flammarion, 1987.

BARRETO, L. Diário do Hospício / O Cemitério dos vivos. São Paulo: Companhia das Letras, 2017.

BAUDELAIRE, C. Les fleurs du mal. Paris: Garnier, 1961.

DERRIDA, J. La voix et le phénomème. Paris: PUF, 1967a.

. De la grammatologie. Paris: Minuit, 1967b.

. Spectres de Marx: l'État de la dette, le travail de deuil et la nouvelle internationale. Paris: Galilée, 1993.

. Des tours de Babel. In: . Psyché: l'invention de l'autre I. Paris: Galilée, 1998.

. Donner la mort. Paris: Galilée, 1999. 
DERRIDA, J. Béliers. Le dialogue ininterrompu: entre deux infinis, le poème. Paris: Galilée, 2003.

. Qu'est-ce qu'une traduction "relevante"? Paris: Herne, 2005a. . Apprendre à vivre enfin. Paris: Galilée, 2005b.

. Introduction. In: HUSSERL, E. L'origine de la géométrie. Traduction et introduction de Jacques Derrida. Paris: PUF, 2009.

FREUD, S. Luto e melancolia. Tradução de Marilene Carone. São Paulo: Cosac Naify, 2013.

GODARD, J-L. JLG/JLG, Autoportrait de décembre. Paris: POL, 1996.

Piero Eyben. Doutor em Literatura. Professor Associado de Teoria da Literatura no Departamento de Teoria Literária e Literaturas, Instituto de Letras, da Universidade de Brasília. Líder do Grupo de Pesquisa "Escritura: linguagem e pensamento", cadastrado no diretório do CNPq. Pesquisador Produtividade CNPq. E-mail: pieroeyben@unb.br.

Recebido em: 12/09/2018

Aceito em: 20/12/2018 